\title{
Preparation of Some Novel Copper(I) Complexes and their Molar Conductances in Organic Solvents
}

\author{
Dip Singh Gill and Dilbag Rana \\ Department of Chemistry, Panjab University, Chandigarh-160 014, India \\ Reprint requests to Prof. D. S. G.; Fax: +91-172-2545074; E-mail: dipgill@yahoo.com
}

Z. Naturforsch. 64a, 269-272 (2009); received September 3, 2008

\begin{abstract}
Attempts have been made to prepare some novel copper(I) nitrate, sulfate, and perchlorate complexes. Molar conductances of these complexes have been measured in organic solvents like acetonitrile (AN), acetone (AC), methanol (MeOH), $N, N$-dimethylformamide (DMF), N,Ndimethylacetamide (DMA), and dimethylsulfoxide (DMSO) at $298 \mathrm{~K}$. The molar conductance data have been analyzed to obtain limiting molar conductances $\left(\Lambda_{\mathrm{o}}\right)$ and ion association constants $\left(K_{A}\right)$ of the electrolytes. The results showed that all these complexes are strong electrolytes in all organic solvents. The limiting ionic molar conductances $\left(\lambda_{+}^{\mathrm{o}}\right)$ for various ions have been calculated using $\mathrm{Bu}_{4} \mathrm{NBPh}_{4}$ as reference electrolyte. The actual radii for copper(I) complex ions are very large and different in different solvents and indicate some solvation effects in each solvent system.
\end{abstract}

Key words: Preparation; Solvation; Organic Solvents; Conductance.

\section{Introduction}

Highly ionic copper(I) salts are unstable in solid form as well as in water and in many organic solvents. This instability has hindered physico-chemical studies of copper(I) salts in many pure and mixed solvents to be performed with confidence [1-9]. Some symmetrical copper(I) perchlorate and tetrafluoroborate complexes though are already known and well stabilized with ligands like acetonitrile, benzonitrile, 2,9-dimethyl-1,10-phenanthroline, but copper(I) nitrate and sulfate complexes have never been studied in solid form. Such complexes are extremely unstable in solution and quickly disproportionate to copper $(0)$ and copper(II) complexes. In continuation with our previous physico-chemical studies of some copper(I) complexes, especially copper(I) perchlorates, we have prepared some novel copper(I) nitrate and sulfate complexes and have made conductometric studies in pure organic solvents so as to comment on the nature of these electrolytes.

\section{Experimental}

Acetonitrile (AN), N,N-dimethylformamide (DMF), and dimethylsulfoxide (DMSO) (99.8\%, $99.5 \%$, and $99.0 \%$, all from E. Merck), acetone (AC) and methanol (MeOH) (both 99.5\%, from Qualigens),
$N, N$-dimethylacetamide (DMA) $(99.5 \%$ from CDH) were purified as reported in [10]. The densities, viscosities, and dielectric constants of the purified solvents are given in Table 1; they agree well with the literature values [10].

Tetraacetonitrile copper(I) perchlorate $\left[\mathrm{Cu}(\mathrm{AN})_{4}\right]-$ $\mathrm{ClO}_{4}$, as before, was prepared under dry nitrogen atmosphere by the reduction of copper(II) perchlorate hexahydrate by copper metal powder in warm acetonitrile by following the method reported by Hathaway et al. [11] and Gill and Cheema [12].

Tetraacetonitrile copper(I) nitrate $\left[\mathrm{Cu}(\mathrm{AN})_{4}\right] \mathrm{NO}_{3}$, which is relatively more difficult to be prepared and stabilized than perchlorate complexes, was prepared under dry nitrogen conditions by reduction of copper(II) nitrate by copper metal powder in warm acetonitrile. On cooling white crystals separated out, which were crystallized from dry acetonitrile. These crystals were dried under vacuum. The prepared copper(I) nitrate crystals remained stable only for a short time and became blue in a few minutes. Copper(I) nitrate solution in dry acetonitrile, however, remained stable for hours which could be used to prepare copper(I) nitrate complexes with other stronger organic ligands than acetonitrile.

Bis-2,9-dimethyl-1,10-phenanthroline copper(I) perchlorate $\left[\mathrm{Cu}(\text { DMPhen })_{2}\right] \mathrm{ClO}_{4}$ and bis-2,9-dimethyl-1,10-phenanthroline copper(I) nitrate $[\mathrm{Cu}-$ 
(DMPhen $\left.)_{2}\right] \mathrm{NO}_{3}$ were prepared by mixing a warm solution of 2,9-dimethyl-1,10-phenanthroline (99\%, Löba) with copper(I) perchlorate and copper(I) nitrate solution in acetonitrile, respectively, in the required proportion. $\left[\mathrm{Cu}(\mathrm{DMPhen})_{2}\right] \mathrm{ClO}_{4}$ was precipitated by using an excess of toluene, and $\left[\mathrm{Cu}(\mathrm{DMPhen})_{2}\right] \mathrm{NO}_{3}$ was recrystallized by using acetone and dried under vacuum. Both these complexes were relatively more stable than the acetonitrile complexes.

Tetrathiourea copper(I) perchlorate $\left[\mathrm{Cu}(\mathrm{TU})_{4}\right] \mathrm{ClO}_{4}$ and tetrathiourea copper(I) nitrate $\left[\mathrm{Cu}(\mathrm{TU})_{4}\right] \mathrm{NO}_{3}$ were prepared by mixing a warm solution of thiourea (99\%, New India Chemical Enterprises, Cochin, India) with copper(I) perchlorate and copper(I) nitrate solutions, respectively, in the required molar ratio.

Dithiourea copper(I) perchlorate $\left[\mathrm{Cu}(\mathrm{TU})_{2}\right] \mathrm{ClO}_{4}$ and dithiourea copper(I) nitrate $\left[\mathrm{Cu}(\mathrm{TU})_{2}\right] \mathrm{NO}_{3}$ were prepared by slow addition of a warm solution of thiourea (99\%, New India Chemical Enterprises) in water and an acetonitrile mixture to copper(I) perchlorate and copper(I) nitrate, respectively, in the required proportion.

The preparation of copper(I) sulfate was very difficult. Copper(I) sulfate could be easily formed in a water/acetonitrile mixture by reduction of copper(II) sulfate in the presence of a few drops of concentrated sulfuric acid. Copper(I) sulfate could be concentrated to $3 \mathrm{M}$. This solution remained stable in the water/acetonitrile mixture. All attempts to precipitate solid copper(I) sulfate from the solution failed. A removal of acetonitrile from the solution lead to the reverse reaction of the equilibrium

$$
2 \mathrm{Cu}^{+} \leftrightarrow \mathrm{Cu}^{2+}+\mathrm{Cu}^{0},
$$

in which copper powder separated out to lead to $\mathrm{Cu}^{2+}$ in solution. Bis-2,9-dimethyl-1,10-phenanthroline copper(I) sulfate $\left[\mathrm{Cu}(\mathrm{DMPhen})_{2}\right]_{2} \mathrm{SO}_{4}$ was prepared by mixing a warm solution of 2,9-dimethyl-1,10phenanthroline with $\left[\mathrm{Cu}(\mathrm{AN})_{4}\right]_{2} \mathrm{SO}_{4}$ solution, generated in situ by the reduction of a warm solution of copper sulfate in acetonitrile.

Tetrabutylammonium tetraphenylborate and tetrabutylammonium perchlorate were prepared and dried by the methods already reported $[8,13]$. The purity of the salts was checked by their elemental, chemical, and spectroscopic analyses. In the UV spectra of all copper salts used for the present study a peak close to $452 \mathrm{~nm}$ in the UV/visible region confirmed the presence of copper(I). The absence of a peak between
Table 1 . Density $\left(d\right.$ in $\left.\mathrm{g} \mathrm{cm}^{-3}\right)$, viscosity $(\eta$ in $\mathrm{cP})$ and dielectric constant $(\varepsilon)$ of some organic solvents at $298 \mathrm{~K}$.

\begin{tabular}{llll}
\hline Solvent & $d / \mathrm{g} \mathrm{cm}^{-3}$ & $\eta / \mathrm{cP}$ & $\varepsilon$ \\
\hline $\mathrm{AN}$ & 0.77685 & 0.341 & 36.0 \\
$\mathrm{AC}$ & 0.78441 & 0.304 & 20.7 \\
MeOH & 0.79103 & 0.545 & 32.6 \\
$\mathrm{DMF}$ & 0.94340 & 0.796 & 37.6 \\
DMA & 0.93648 & 0.919 & 37.8 \\
DMSO & 1.09601 & 1.990 & 46.7 \\
\hline
\end{tabular}

750 to $850 \mathrm{~nm}$ confirmed the absence of any traces of $\mathrm{Cu}(\mathrm{II})$ in the sample. The purity of salts has also been checked by using $\mathrm{KMnO}_{4}$ titrations and sulfate estimates.

The molar conductances of various salts have been measured at $1000 \mathrm{~Hz}$, frequency at a temperature of $(298.15 \pm 0.01) \mathrm{K}$, with a digital conductivity meter (Model NDC-732, Naina Electronics, Chandigarh, India). The details of the experimental procedure of conductance measurements have been reported earlier $[13,14]$. The overall accuracy of the conductance measurements was found to be $\pm 0.2 \%$. As the precision of our conductance data was not better than $\pm 0.2 \%$, the use of any extended conductance equations, which demand an accuracy in the conductance data much better than $\pm 0.1 \%$, was not considered worthwhile. The conductivity $\Lambda_{0}$ for some of these salts in AN already available are reported in parentheses for comparison with the present values. Good agreement has been found between the presently measured and the literature values [15-18].

Viscosity measurements have been done by using an Ubbelohde suspended level viscometer with a flow time of 231 for water at $298 \mathrm{~K}$. The viscometer was calibrated with the method reported earlier [8]. Also the details of the experimental procedure of viscosity measurements were the same as reported earlier [8]. The reproducibility of the viscosity measurements was better than $\pm 0.1 \%$.

The densities of solvent mixtures and solutions were measured using an Anton Paar digital density meter Model-60 and a calibrated cell with reproducibility of $\pm 0.00001 \mathrm{~g} \mathrm{~cm}^{-3}$. The permittivities were measured at $2 \mathrm{MHz}$ using a Radelkis Hungury OH-301 dielectrometer.

\section{Results and Discussion}

\subsection{Molar Conductance Measurements}

All mentioned copper(I) complexes are strong electrolytes in organic solvents. The molar conductances 
Table 2. $\Lambda_{\mathrm{O}}$ (in S cm${ }^{2} \mathrm{~mol}^{-1}$ ) and $K_{\mathrm{A}}$ (in $\mathrm{dm}^{3} \mathrm{~mol}^{-1}$ ) for some copper(I) perchlorate, nitrate and sulfate complexes in AN, $\mathrm{AC}, \mathrm{MeOH}, \mathrm{DMA}, \mathrm{DMF}$, and DMSO at $298 \mathrm{~K}$.

\begin{tabular}{|c|c|c|c|c|c|c|c|c|c|c|c|c|}
\hline \multirow[t]{3}{*}{$\overline{\text { Salt }}$} & \multicolumn{12}{|c|}{ Solvent } \\
\hline & \multicolumn{2}{|l|}{$\mathrm{AN}$} & \multicolumn{2}{|c|}{$\mathrm{AC}$} & \multicolumn{2}{|c|}{$\mathrm{MeOH}$} & \multicolumn{2}{|c|}{ DMA } & \multicolumn{2}{|c|}{$\mathrm{DMF}$} & \multicolumn{2}{|c|}{ DMSO } \\
\hline & $\Lambda_{\mathrm{o}}$ & $K_{\mathrm{A}}$ & $\Lambda_{\mathrm{o}}$ & $K_{\mathrm{A}}$ & $\Lambda_{\mathrm{o}}$ & $K_{\mathrm{A}}$ & $\Lambda_{\mathrm{o}}$ & $K_{\mathrm{A}}$ & $\Lambda_{\mathrm{o}}$ & $K_{\mathrm{A}}$ & $\Lambda_{\mathrm{o}}$ & $K_{\mathrm{A}}$ \\
\hline $\mathrm{Bu}_{4} \mathrm{NBPh}_{4}$ & $\begin{array}{c}119.6 \\
(119.8)[15]\end{array}$ & - & 132.5 & - & 73.5 & - & $\begin{array}{c}43.8 \\
(44.3)[16]\end{array}$ & 56 & 50.7 & - & 21.6 & - \\
\hline $\mathrm{Bu}_{4} \mathrm{NClO}_{4}$ & $\begin{array}{c}165.9 \\
(164.8)[16]\end{array}$ & - & 182.7 & 80 & 105.1 & 43 & 62.5 & 30 & 77.2 & 12 & 35.2 & - \\
\hline$\left[\mathrm{Cu}(\mathrm{AN})_{4}\right] \mathrm{ClO}_{4}$ & $\begin{array}{c}168.0 \\
(168.4)[17]\end{array}$ & - & 202.2 & & 117.1 & 53 & 62.8 & - & 81.8 & 44 & 34.6 & - \\
\hline$\left[\mathrm{Cu}(\mathrm{AN})_{4}\right] \mathrm{NO}_{3}$ & 176.7 & & 202.3 & & 115.7 & 27 & 68.4 & & 87.3 & 8 & 39.5 & - \\
\hline$\left[\mathrm{Cu}(\mathrm{DMPhen})_{2}\right] \mathrm{ClO}_{4}$ & $\begin{array}{c}152.6 \\
(155.6)[18] \\
(159.4)[20]\end{array}$ & - & 178.6 & & 104.1 & & 67.6 & & 76.6 & & 35.3 & - \\
\hline$\left[\mathrm{Cu}(\mathrm{DMPhen})_{2}\right] \mathrm{NO}_{3}$ & 161.3 & 27 & 178.7 & 525 & 102.7 & 368 & 73.2 & 28 & 82.1 & 27 & 40.2 & 7 \\
\hline$\left[\mathrm{Cu}(\mathrm{DMPhen})_{2}\right]_{2} \mathrm{SO}_{4}$ & 199.9 & & 248.9 & & 142.0 & & 97.2 & & 104.2 & & 45.5 & \\
\hline$\left[\mathrm{Cu}(\mathrm{TU})_{4}\right] \mathrm{ClO}_{4}$ & 167.7 & 13 & 193.5 & 176 & 103.1 & 137 & 64.5 & - & 85.8 & - & 39.8 & - \\
\hline$\left[\mathrm{Cu}(\mathrm{TU})_{4}\right] \mathrm{NO}_{3}$ & 176.4 & & 193.6 & & 101.7 & 127 & 70.1 & 198 & 91.3 & 130 & 44.7 & \\
\hline$\left[\mathrm{Cu}(\mathrm{TU})_{2}\right] \mathrm{ClO}_{4}$ & 164.4 & & 185.5 & & 108.0 & & 60.9 & & 78.9 & & 35.1 & \\
\hline$\left[\mathrm{Cu}(\mathrm{TU})_{2}\right] \mathrm{NO}_{3}$ & 173.1 & & 185.6 & & 106.6 & & 67.1 & & 84.4 & & 40.0 & \\
\hline
\end{tabular}

Table 3. $\lambda^{\mathrm{o}}$ (in $\mathrm{S} \mathrm{cm}^{2} \mathrm{~mol}^{-1}$ ) and $r_{\mathrm{i}}$ (in $\mathrm{nm}$ ) values for some copper(I) ions in $\mathrm{AN}, \mathrm{AC}, \mathrm{MeOH}, \mathrm{DMA}, \mathrm{DMF}$, and DMSO at $298 \mathrm{~K}$.

\begin{tabular}{|c|c|c|c|c|c|c|c|c|c|c|c|c|}
\hline \multirow[t]{3}{*}{ Ion } & \multicolumn{12}{|c|}{ Solvent } \\
\hline & \multicolumn{2}{|c|}{$\mathrm{AN}$} & \multicolumn{2}{|c|}{$\mathrm{AC}$} & \multicolumn{2}{|c|}{$\mathrm{MeOH}$} & \multicolumn{2}{|c|}{ DMA } & \multicolumn{2}{|c|}{ DMF } & \multicolumn{2}{|c|}{ DMSO } \\
\hline & $\lambda^{0}$ & $r_{\mathrm{i}}$ & $\lambda^{o}$ & $r_{\mathrm{i}}$ & $\lambda^{\circ}$ & $r_{\mathrm{i}}$ & $\lambda^{\circ}$ & $r_{\mathrm{i}}$ & $\lambda^{\circ}$ & $r_{\mathrm{i}}$ & $\lambda^{o}$ & $r_{\mathrm{i}}$ \\
\hline $\mathrm{Bu}_{4} \mathrm{~N}^{+}$ & 62.4 & 0.50 & 69.1 & 0.51 & 37.2 & 0.52 & 22.9 & 0.51 & 26.5 & 0.51 & 11.3 & 0.51 \\
\hline$\left[\mathrm{Cu}(\mathrm{AN})_{4}\right]^{+}$ & 64.5 & 0.49 & 88.6 & 0.41 & 49.2 & 0.42 & 23.2 & 0.51 & 31.1 & 0.45 & 10.7 & 0.46 \\
\hline$\left[\mathrm{Cu}(\mathrm{DMPhen})_{2}\right]^{+}$ & 49.1 & 0.61 & 65.0 & 0.52 & 36.2 & 0.53 & 28.0 & 0.64 & 25.9 & 0.52 & 11.4 & 0.54 \\
\hline$\left[\mathrm{Cu}(\mathrm{TU})_{4}\right]^{+}$ & 64.2 & 0.49 & 79.9 & 0.44 & 35.2 & 0.55 & 24.9 & 0.48 & 35.1 & 0.42 & 15.9 & 0.43 \\
\hline$\left[\mathrm{Cu}(\mathrm{TU})_{2}\right]^{+}$ & 60.9 & 0.51 & 71.9 & 0.48 & 40.1 & 0.49 & 21.9 & 0.53 & 28.2 & 0.49 & 11.2 & 0.50 \\
\hline $\mathrm{BPh}_{4}^{-}$ & 57.2 & 0.54 & 63.4 & 0.53 & 36.3 & 0.56 & 20.9 & 0.55 & 24.2 & 0.55 & 10.3 & 0.55 \\
\hline $\mathrm{ClO}_{4}^{-}$ & 103.5 & 0.35 & 113.6 & 0.34 & 67.9 & 0.34 & 39.6 & 0.35 & 50.7 & 0.33 & 23.9 & 0.32 \\
\hline $\mathrm{NO}_{3}^{-}$ & 112.2 & 0.35 & 113.7 & 0.34 & 66.5 & 0.34 & 45.2 & 0.32 & 56.2 & 0.31 & 28.8 & 0.31 \\
\hline $\mathrm{SO}_{4}^{2-}$ & 101.7 & 0.35 & 118.9 & 0.33 & 69.6 & 0.33 & 41.2 & 0.34 & 52.4 & 0.32 & 22.7 & 0.31 \\
\hline
\end{tabular}

$(\Lambda)$ of $\mathrm{Bu}_{4} \mathrm{NBPh}_{4}, \mathrm{Bu}_{4} \mathrm{NClO}_{4},\left[\mathrm{Cu}(\mathrm{AN})_{4}\right] \mathrm{ClO}_{4}$, [Cu$\left.(\mathrm{AN})_{4}\right] \mathrm{NO}_{3},\left[\mathrm{Cu}(\mathrm{DMPhen})_{2}\right] \mathrm{ClO}_{4},\left[\mathrm{Cu}(\mathrm{DMPhen})_{2}\right]-$ $\mathrm{NO}_{3}, \quad\left[\mathrm{Cu}(\mathrm{TU})_{4}\right] \mathrm{ClO}_{4}, \quad\left[\mathrm{Cu}(\mathrm{TU})_{4}\right] \mathrm{NO}_{3}, \quad\left[\mathrm{Cu}(\mathrm{TU})_{2}\right]-$ $\mathrm{ClO}_{4},\left[\mathrm{Cu}(\mathrm{TU})_{2}\right] \mathrm{NO}_{3}$, and $\left[\mathrm{Cu}(\mathrm{DMPhen})_{2}\right]_{2} \mathrm{SO}_{4}$ have been measured in the concentration range $(1-125)$ $\cdot 10^{-4} \mathrm{~mol} \mathrm{dm}^{-3}$ in pure organic solvents like AN, AC, MeOH, DMF, DMA, and DMSO at $298 \mathrm{~K}$. The measured data have been analyzed by a least square treatment using a Pentium II PC and following the Shedlovsky method [19] to evaluate the limiting molar conductances $\left(\Lambda_{0}\right)$ of the electrolytes. $\Lambda_{0}$ values so obtained are reported in Table 2. The experimentally measured physical parameters of all organic solvents used for the analysis of the data are reported in Table 1. The ionic association constants $\left(K_{\mathrm{A}}\right)$ show that copper(I) nitrate and sulfate complexes are relatively more associated than the corresponding perchlorate complex.

\subsection{Limiting Ion Conductances}

The limiting ionic molar conductances $\left(\lambda_{ \pm}^{o}\right)$ have been calculated, using $\mathrm{Bu}_{4} \mathrm{NBPh}_{4}$ as reference electrolyte, with the help of the following equations:

$$
\begin{gathered}
\frac{\lambda^{\mathrm{o}}\left(\mathrm{Bu}_{4} \mathrm{~N}^{+}\right)}{\lambda^{\mathrm{o}}\left(\mathrm{Ph}_{4} \mathrm{~B}^{-}\right)}=\frac{5.35-\left(0.0103 \varepsilon+r_{y}\right)}{5.00-\left(0.0103 \varepsilon+r_{y}\right)} \\
\Lambda_{\mathrm{o}}\left(\mathrm{Bu}_{4} \mathrm{NBPh}_{4}\right)=\lambda_{\mathrm{o}}\left(\mathrm{Bu}_{4} \mathrm{~N}^{+}\right)+\lambda_{\mathrm{o}}\left(\mathrm{Ph}_{4} \mathrm{~B}^{-}\right) .
\end{gathered}
$$

The limiting ionic molar conductances for the $\mathrm{Bu}_{4} \mathrm{~N}^{+}$ and $\mathrm{Ph}_{4} \mathrm{~B}^{-}$ions are obtained from the above equations, and these values have been used to calculate the limiting ionic molar conductances of all other ions on the basis of Kohlrausch's law of independent migration of ions. Using this method for the $\Lambda_{\mathrm{o}}$ values, the $\lambda_{i}^{\mathrm{o}}$ values for the various ions of Table 2 have been computed and recorded in Table 3. 


\subsection{Actual Radii for Some Copper(I) Cations}

To understand the solvation behaviour of the different ions, the solvated radii $\left(r_{\mathrm{i}}\right)$ for the various ions have been calculated using Gill's modification of Stokes' law [21]:

$$
r_{\mathrm{i}}=\frac{|Z| F^{2}}{6 \pi \eta N \lambda_{i}^{\mathrm{o}}}+0.0103 \varepsilon+r_{y} .
$$

Here $r_{\mathrm{i}}$ is the actual radius of the ion in solution, $\varepsilon$ is the dielectric constant of the medium, $r_{y}$ is the adjustable parameter, and all other symbols have their usual meaning. For associated and hydrogen-bound solvents $r_{y}$ has been recommended to be $0.113 \mathrm{~nm}$ and for non-associated or dipolar aprotic solvents as $0.085 \mathrm{~nm}$ [21]. Since in the present work dipolar aprotic solvents have been used as solvent systems, therefore $r_{y}$ has been used as $0.085 \mathrm{~nm}$. Using the $\lambda^{0}$ values from Table 3, the $r_{\mathrm{i}}$ values for various ions have

[1] S.P. Narula, P. S. Guraya, S.P. Jauhar, and G. Delessale, Indian J. Chem. 20 A, 129 (1981).

[2] A. D. Aparano, F. Accascino, and R. M. Fuoss, J. Sol. Chem. 19, 65 (1990).

[3] B. P. Dey and S. Lahiri, Ind. J. Chem. 25 A, 136 (1986).

[4] D. S. Gill, L. Rodehueser, and J. J. Delpuech, J. Chem. Soc. Faraday Trans. 86, 2847 (1990).

[5] D. S. Gill, T. I. Quickenden, L. Byrne, V. Pathania, and B. K. Vermani, J. Mol. Liquids 111, 85 (2004).

[6] D. S. Gill, A. Kumari, R. Gupta, J. K. Puri, and S.P. Jauhar, Z. Phys. Chem. 219, 1099 (2005).

[7] D. S. Gill, V. Pathania, B. K. Vermani, and R.P. Sharma, Z. Phys. Chem. 217, 739 (2003).

[8] D.S. Gill, H. Anand, A. Kumari, and J. K. Puri, Z. Naturforsch. 59a, 615 (2004).

[9] D. S. Gill, V. Pathania, A. Kumari, H. Anand, and S. P. Jauhar, Z. Phys. Chem. 218, 857 (2004).

[10] J. A. Riddick, W. B. Bugner, and T. K. Sakano, Organic Solvents, Physical Properties and Methods of Purification, $4^{\text {th }}$ ed., Wiley Interscience, New York 1986.

[11] B. J. Hathaway, D. G. Holah, and J.D. Postlewaite, J. Chem. Soc., 3215 (1961). been calculated in different solvent systems which is reported in Table 3. The actual radii of the various ions indicated that tetrabutylammonium and tetraphenylborate ions are not solvated, as they have the same $r_{\mathrm{i}}$ values in all solvents, and these constant values are equal to their crystallographic radii $\left(r_{c}=0.50 \mathrm{~nm}\right.$ and $r_{a}=0.535 \mathrm{~nm}$, respectively). These two ions are not solvated in many dipolar aprotic solvents due to their large size. The anions are much less solvated. The solvation radii for $\mathrm{ClO}_{4}^{-}, \mathrm{NO}_{3}^{-}$and $\mathrm{SO}_{4}^{2-}$ are almost comparable in all solvents indicating the solvation of these ions to the same extent. The relative sizes of all copper(I) complexes are larger, but vary from solvent to solvent. This shows some solvation effect on these cations.

\section{Acknowledgement}

Dilbag Rana thanks the UGC for the award of SRF.

[12] D. S. Gill and J. S. Cheema, Electrochim. Acta 27, 1267 (1982).

[13] D. S. Gill, A. N. Sharma, and H. Schneider, J. Chem. Soc. Faraday Trans. 78, 465 (1982).

[14] D. S. Gill and M. B. Sekhri, J. Chem. Soc. Faraday Trans. 1 78, 119 (1982).

[15] A. B. Brown and R. M. Fuoss, J. Phys. Chem. 64, 1341 (1960).

[16] D. S. Gill, N. Kumari, and M.S. Chauhan, J. Chem. Soc. Faraday Trans. 1 81, 687 (1985).

[17] H. L. Yeager and B. Kratochvil, J. Phys. Chem. 73, 1963 (1969).

[18] D. S. Gill, K. S. Arora, B. Singh, M. S. Bakshi, and M. S. Chauhan, J. Chem. Soc. Faraday Trans. 87, 1159 (1991).

[19] R. M. Fuoss and T. Shedlovsky, J. Am. Chem. Soc. 71, 1496 (1949).

[20] K. Miyoshi and T. Tominaga, J. Phys. Chem. 77, 819 (1973).

[21] D. S. Gill, J. Chem. Soc. Faraday Trans. 1 77, 751 (1981). 